\title{
Análise dos modos de falha e efeitos na otimização dos fatores de produção no cultivo agrícola: subprocesso colheita da canola
}

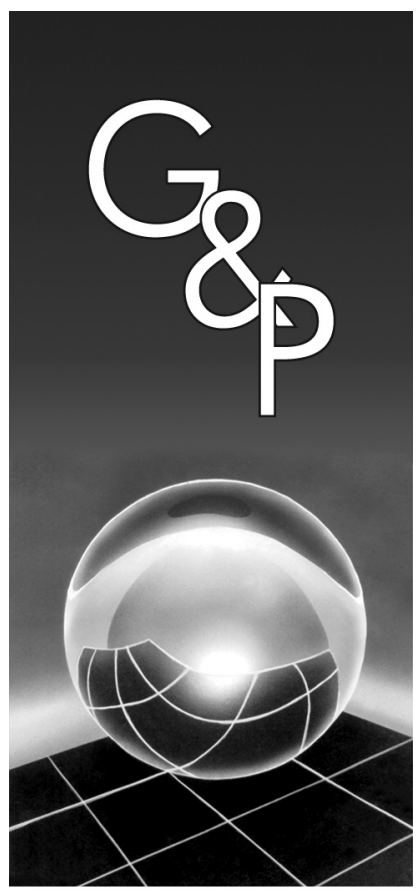

Leandro Cantorski da Rosa

Marcos Garrafa

\section{Resumo}

O setor agrícola passa por um intenso processo de transformações e modernização, mas ainda apresenta certo atraso em relação aos demais segmentos da economia, sobretudo na utilização de novas tecnologias e técnicas administrativas, que reflete em problemas que devem ser considerados. Este artigo apresenta uma metodologia para priorizar modos de falha e seus efeitos associados, para a determinação de ações preventivas, visando aperfeiçoar processos no cultivo agrícola de canola, usando a técnica FMEA, com foco no subprocesso colheita. O setor agrícola possui algumas características próprias, razão pela qual foram feitas algumas adaptações para análise deste tipo de processo. A aplicação foi ilustrada através de um estudo de caso em uma lavoura de canola na Escola-Fazenda da Sociedade Educacional Três de Maio (SETREM). A determinação de prioridades dos modos de falha foi feita de forma comparativa, pelo NPR (número de prioridade de risco) e de um método gráfico.

Palavras-chave: FMEA. Cultura da canola. Colheita da canola. Priorização de falhas.

\section{Introdução}

A canola é uma planta da família das crucíferas, gênero Brassica, originária de uma seleção de cultivares de colza, possuindo em seus grãos teores de óleo que variam entre 40 e $46 \%$, com elevada qualidade alimentar, apresentando menor teor de gorduras saturadas. No Brasil, é cultivada apenas a canola de primavera, da espécie Brassica napus L., desenvolvida por melhoramento genético convencional da colza (TOMM, 2003). Seu óleo é usado na alimentação humana de forma in natura, em saladas, para realização de frituras em geral, fabrico de margarinas e para realização de cortes em outros óleos.

O cultivo de canola no Brasil é relativamente recente e a área cultivada com a cultura tem demonstrado potencial de significativo aumento nos Estados do Sul do Brasil (TOMM, 2000). No entanto, gargalos de produção têm sido evidenciados, fazendo-se necessárias suas detecções. Para tanto, é importante conhecer detalhes da condução de seu cultivo, buscando a sua viabilização.

A técnica FMEA (failure mode and effect analysis), é uma importante técnica para definir, identificar e eliminar falhas conhecidas ou potenciais, de sistemas, projetos, processos, produtos e serviços antes que estas atinjam o cliente.
As atividades do setor primário e os processos de cultivo agrícola em particular, caracterizam-se por não permitir mensuração das práticas adotadas visando posterior correção, uma vez que elas consumam-se por si próprias, necessitando, portanto, de ações preventivas para eliminação dos possíveis defeitos delas decorrentes. Embora não tenham sido encontradas referências a respeito da aplicação da FMEA em processos de cultivo agrícola, alguns aspectos devem ser considerados a fim de sustentar essa possibilidade. Assim, inicialmente, é necessário observar que o método está baseado em ações preventivas.

Nos estudos referentes à produção vegetal, é usual a aplicação do princípio dos fatores limitativos ou Lei de Liebig. Segundo este princípio, "o nível de produção agrícola não pode ser maior do que o possibilitado pelo mais limitativo dos fatores essenciais ao crescimento vegetal" (BRADY, 1979). Nessa perspectiva, pode-se afirmar que, uma vez listadas as causas interferentes no processo produtivo, é necessário detectar quais se apresentam como limitantes principais, portanto prioritárias de atenção. Este argumento aproxima a abordagem da FMEA à gestão de processos agrícolas. 
Esta pesquisa teve como objetivo demonstrar a viabilidade do uso da técnica FMEA, na determinação de ações preventivas para a maximização dos fatores de produção no processo de cultivo de canola com foco no subprocesso colheita.

\section{Análise dos modos de falha e efeitos}

A análise dos modos de falha e efeitos, denominada no meio industrial por FMEA, consiste num método de análise de projetos (de produtos ou processos, industriais e/ ou administrativos). A técnica é usada para antecipar falhas que podem ocorrer em um produto, peça ou processo, permitindo atuar-se antecipadamente na causa para que a falha ou defeito não venha a ocorrer. A descrição da FMEA aprofunda mais, considerando que ela se destina, além do já explicitado, a documentar todo o processo.

As principais etapas para execução da FMEA são: definir o processo ou produto a ser analisado; definir a(s) função(es) do processo ou produto; identificar os possíveis modos de falha; identificar os possíveis efeitos de cada modo de falha para as pessoas que sofrem impacto do processo ou produto; estimar a severidade dessas falhas; identificar as causas raízes das possíveis falhas; estimar a probabilidade de ocorrência da falha; identificar o meio de detecção do modo de falha; estimar a probabilidade dessa falha ser detectada antecipadamente; determinar as prioridades; definir planos de ação para diminuir o risco (HELMANN; ANDERY, 1995).

Aplicações da ferramenta FMEA, como apoio ao gerenciamento de processos, têm sido relatadas por pesquisadores de diversas áreas. Destaca-se seu uso como suporte ao gerenciamento de riscos em serviços hospitalares (PAPARELLA, 2007; TRUCCO; CAVALLIN, 2006; REID, 2005; REILING; KNUTZEN; STOECKLEIN, 2003; SPATH, 2003). Welborn (2007) relata sua aplicação à avaliação de riscos associados para estratégia de terceirização. Hsiao (2002) propõe uma integração da FMEA ao QFD (quality function deployment), DFA (design for assembly) e AHP (analytic hierarchy process) para uma análise das falhas no projeto de um brinquedo. Price e Taylor (2002) relatam a aplicação da FMEA para estudo de falhas em sistemas complexos por meio da simulação. Sua aplicação na análise de falhas existentes em etapas de sistemas agroindustriais é relativamente recente (BERTOLINI; BEVILACQUA; MASSINI, 2006; GARRAFA, 2005; GARRAFA; ROSA, 2004).

\subsection{Priorização das causas de falhas potenciais}

Ao identificar os possíveis efeitos de cada modo de falha, deve-se classificar os modos de falha quanto à severidade dos efeitos por eles causados. Ao definir as causas raízes das possíveis falhas, deve-se identificar os atuais meios de prevenção, que reduzem a probabilidade de ocorrência dessa falha. Com base nestas informações e históricos de ocorrência da falha, cada causa é classificada quanto a sua probabilidade de ocorrência. Ao identificar o meio de detecção do modo de falha, ou seja, a capacidade de identificá-la antes que o efeito final venha a ocorrer, deve-se associá-lo a um valor pré-determinado.

O método mais usado para determinar as prioridades é por meio do NPR (número de prioridade de risco), obtido pela multiplicação da pontuação dada para as classificações de severidade, ocorrência e detecção. Obtêm-se assim valores situados numa faixa crescente, que indicam desde baixíssimo risco até risco crítico para o resultado mais elevado (HELMAN; ANDERY, 1995). A escala 1-10 é usada com frequência na pontuação da severidade, ocorrência e detecção, trazendo mais precisão e diferenciação entre resultados, mas a escala 1-5 facilita o consenso entre os membros da equipe envolvida na análise (WELBORN, 2007).

Vários pesquisadores relatam adaptações nas tabelas para obtenção dos valores correspondentes à severidade, probabilidade de ocorrência e detecção para aplicação em áreas bem diversas como: Welborn (2007), para análise de falhas associadas à terceirização; McCain (2006), no desenvolvimento de projetos na área de serviços; Bertolini, Bevilacqua e Massini (2006), ponderaram a severidade e probabilidade de ocorrência a partir de critérios estabelecidos em norma norte-americana; Reid (2005) apresenta critérios para a área da saúde; Cotnareanu (1999) mostra adaptações para análise de falhas em atividades de manutenção preventiva; Vandenbrande (1998) introduz ajustes para uso da FMEA na avaliação de processos que estejam associados a riscos ambientais. Na estruturação da FMEA para análise do subprocesso colheita da canola, foram definidas tabelas (Tabelas 1 a 3) de parâmetros de avaliação do critério severidade dos efeitos decorrentes das falhas, probabilidade de ocorrência das causas identificadas e probabilidade de detecção das falhas (GARRAFA, 2005; GARRAFA; ROSA, 2004).

Embora o método convencional seja bastante usado, a literatura apresenta algumas críticas quanto à forma de cálculo do NPR e à forma de priorização das medidas necessárias à redução do risco (FERNANDES, 2005; GARRAFA, 2005; LEAL et. al., 2005; PILLAY; WANG, 2003; PUENTE; PINO; PRIORE; FUENTE, 2002; SANKAR; PRABHU, 2001; CHANG; LIU; WEI, 2001; PALADY, 1997; BEN-DAYA; RAOUF, 1996; GILCHRIST, 1993).

Algumas alternativas têm sido propostas em substituição ao método convencional: Yadav, Sing e Goel (2006) propõem a decomposição de sistemas nas dimensões física, funcional e temporal e usam os valores sugeridos pela FMEA na elaboração de uma matriz bi ou tridimensional; Seyed-Hosseini, Safei e Asgharpour 
(2006) apresentam modificações no sistema de priorização das falhas em sistemas mecânicos, baseado na relação entre efeitos ou influências dos critérios de severidade sugeridos; Lee (2006) desenvolveu um modelo quantitativo para avaliação dos fatores de risco de segurança do transporte aéreo com a integração da FMEA com a linguagem fuzzy; Guimarães e Lapa (2004) apresentam uma análise de confiabilidade num subsistema de uma instalação nuclear, fazendo um estudo comparativo entre o sistema de priorização NPR e o sistema de inferência fuzzy, mostrando as vantagens deste último; Pillay e Wang (2003) desenvolveram um modelo modificado com o uso da teoria grey e regras fuzzy para análise de falhas operacionais em barcos de pesca; Sankar e Prabhu (2001) propõem uma abordagem baseada no RPR (risk priority rank) com mil combinações de severidade, ocorrência e detecção tabuladas com o auxílio de especialistas.

Palady (1997) propõe a elaboração de um gráfico, usando as escalas de avaliação da severidade e ocorrência, ambas com igual comprimento, sendo a primeira colocada no eixo horizontal e a segunda no eixo vertical e salienta que a equipe deve buscar os mais altos graus de severidade e os mais altos índices de ocorrência. $\mathrm{O}$ gráfico é dividido em regiões, que situam as falhas de

Tabela 1. Parâmetros de avaliação do critério severidade (S).

\begin{tabular}{lc}
\hline \multicolumn{1}{c}{ Critério } & Grau de severidade \\
\hline Perda imperceptível na produção & 1 \\
Diminuição em até 5\% na produção & 2 \\
Diminuição em 5 a 20\% na produção & 3 \\
Diminuição em 20 a 50\% na produção & 4 \\
Diminuição superior a 50\% na produção & 5 \\
\hline
\end{tabular}

Tabela 2. Parâmetros de avaliação do critério ocorrência $(\mathrm{O})$.

\begin{tabular}{lc}
\hline \multicolumn{1}{c}{ Probabilidade de falha } & Índice de ocorrência \\
\hline Remota: ocorrência de falha é improvável & 1 \\
Baixa: ocorrência relativa de poucas falhas & 2 \\
Moderada: ocorrência ocasional de falhas & 3 \\
Alta: ocorrência frequente de falhas & 4 \\
Muito alta: ocorrência persistente de falhas & 5 \\
\hline
\end{tabular}

Tabela 3. Parâmetros de avaliação do critério detecção (D).

\begin{tabular}{lc}
\hline Probabilidade de detecção da falha & Índice de detecção \\
\hline Quase certamente & 1 \\
Alta & 2 \\
Moderada & 3 \\
Remota & 4 \\
Absoluta incerteza & 5 \\
\hline
\end{tabular}

alta, média e baixa prioridade. Estas regiões devem ser estabelecidas pela equipe FMEA a partir da definição de pontos divisores das fronteiras das áreas de prioridade de forma coerente com a política da qualidade e os procedimentos da organização.

\section{0 ambiente da pesquisa}

O estudo proposto tem como base de análise o cultivo de canola, realizado no ano de 2006, na Escola-Fazenda da Sociedade Educacional Três de Maio (SETREM) mantenedora do curso técnico em agropecuária, situada na localidade de Esquina Motta, município de Independência, RS. Portanto, pesquisou-se um fenômeno dentro do seu contexto real, no qual as condições contextuais referem-se ao objeto de estudo (YIN, 2005).

Na estruturação da FMEA aplicada ao cultivo da canola, contou-se com a colaboração de uma equipe denominada "equipe FMEA", incluindo os pesquisadores, os clientes do processo estudado e os envolvidos em sua execução (engenheiro agrônomo, responsável técnico do empreendimento, operador das máquinas, assistente de operação, um técnico em agropecuária - auxiliar no acompanhamento técnico do processo, um técnico em agropecuária representante da empresa fornecedora de insumos e compradora da produção). As análises ocorreram sob a ótica de variadas perspectivas, haja vista a multiplicidade das fontes, aumentando a credibilidade das conclusões alcançadas, caracterizando um estudo qualitativo.

\section{Análise e discussão dos resultados}

A possibilidade da canola vir a participar com sucesso de um sistema de rotação de culturas envolvendo além do trigo, a soja e o milho, é concreta, uma vez que, sendo ela de família diferente, pode auxiliar na supressão de ervas daninhas das demais culturas (especialmente gramíneas), bem como na diminuição de fonte de inóculo de patógenos tradicionalmente presentes na cultura do trigo, o que tende a acarretar diminuição no uso dos produtos químicos usados no controle destes (GARRAFA, 2005).

A canola teve sua área de cultivo diminuída no Brasil e no Rio Grande do Sul nos últimos anos. Um dos fatores contribuintes é seu manejo inadequado por parte dos produtores rurais, falha eminentemente de tecnologia de processo, passível de correção a partir de inclusão de ferramentas da qualidade no processo produtivo.

O processo produtivo da canola divide-se nos subprocessos escolha da área e insumos, sistematização da área de cultivo, semeadura, tratos culturais e colheita. No subpro- 
cesso escolha da área e insumos para a semeadura, deve-se considerar as condições de solo (topografia, profundidade, rotação de culturas), dimensionamento do equipamento, tecnologia da cultura (adubação conforme análise de solo, cultivares e densidade de sementes) e disponibilidade de insumos adequados no mercado. No subprocesso sistematização da área de cultivo, considera-se o sistema de controle da erosão e manejo das plantas invasoras e insetos. No subprocesso semeadura, consideram-se as condições de solo e a distribuição uniforme de fertilizantes e sementes efetuada por semeadeira, tracionada mecanicamente. $\mathrm{O}$ subprocesso tratos culturais requer atenção às atividades de controle de plantas daninhas, insetos-praga e doenças, além da aplicação de fertilizante nitrogenado em cobertura. E, no subprocesso colheita, deve considerar-se o momento ideal de colheita e a regulagem da colheitadeira automotriz.

A estruturação da FMEA para o subprocesso colheita da canola, consta no Apêndice 1. Neste subprocesso, foram identificados 28 diferentes modos de falha, listados na segunda coluna e um ou mais possíveis efeitos associados a cada modo de falha (coluna 3 ).

Foram então estimados os índices de severidade para cada efeito, com base nas notas atribuídas de forma consensual pela equipe FMEA, diante de sua experiência no manejo da cultura, com base nos parâmetros da Tabela 1. Para justificar os valores correspondentes aos índices de severidade, são detalhadas aqui duas situações:

a) no primeiro modo de falha identificado do Apêndice 1, "colheita com teor de umidade dos grãos maior que 18\%" - a colheita da canola deve ser efetuada com umidade máxima de $18 \%$. Colheita com umidade mais elevada acarreta excessivos descontos no volume físico dos grãos. Para determinar o ponto ideal de colheita, deve-se monitorar diariamente a umidade a partir do momento em que o terço mediano do caule principal apresentar de 40 a $60 \%$ das sementes com cor marrom (TOMM, 2003). Grãos úmidos representam presença de síliquas verdes que não debulham ou então geram grãos verdes, considerados impurezas, aumentando as perdas. As empresas compradoras do grão adotam tabelas de desconto (redução da produção) por excesso de umidade - de 13 a $25 \%$ de umidade, desconta-se $1 \%$ a cada $1 \%$ de umidade; a partir de $25 \%$, descontam-se $2 \%$ a cada $1 \%$ de umidade; e

b) no modo de falha de número 24 , "não regulagem das peneiras durante a operação de colheita" - os ajustes na colhedora devem ser feitos várias vezes durante o dia, pois as variações da temperatura e umidade alteram o teor de umidade da palha e dos grãos. Uma regra prática indica que cada 23 grãos de canola perdidos por metro quadrado de área colhida correspondem à perda aproximada de um quilograma por hectare (TOMM, 2007).

Nas colunas 5 a 9, constam, respectivamente, a listagem das possíveis causas de cada modo de falha potencial, o índice de ocorrência estimado para cada modo de falha, as medidas técnicas para detecção e prevenção, o índice de detecção estimado para cada modo de falha e os valores calculados de NPR para cada efeito associado aos modos de falha. Os índices de ocorrência e detecção foram também estimados com base nas notas atribuídas de forma consensual pela equipe FMEA (Tabelas 2 e 3 ).

A equipe FMEA, em duas reuniões, com auxílio de um diagrama de causa e efeito, listou todas as possíveis causas de falha de cada modo de falha potencial no subprocesso estudado, que estão descritas no Apêndice 2.

Optou-se pela metodologia proposta por Palady (1997) para priorizar os modos de falha potenciais, no intuito de comparar ao resultado obtido com o método tradicional. Adotou-se uma codificação referente aos modos de falha, aos seus efeitos e causas de falha para simplificação do trabalho (grifados no Apêndice 1).

Foi estabelecido, pela equipe envolvida no projeto, que o grau de severidade igual a cinco (redução superior a 50\% na produção) e o grau cinco da escala de ocorrência devem ser considerados como pontos iniciais da fronteira de alta prioridade no gráfico. A região de média prioridade foi delimitada pela ligação dos pontos três da escala de severidade e quatro da escala de ocorrência (Figura 1).

$\mathrm{Na}$ Figura 1, verificam-se quatro modos potenciais de falha com alta prioridade de risco no subprocesso colheita de canola, gerando oito efeitos merecedores de atenção especial. Estas prioridades foram ordenadas na Tabela 4 em correspondência com os valores calculados de NPR (Apêndice 1), notando-se uma divergência nas prioridades 4 e 5 .

Comparando-se algumas características importantes entre os dois métodos usados na pesquisa, conclui-se que o método tradicional, baseado no NPR, apresenta 120 resultados possíveis entre os valores 1 e 1000 (SANKAR; PRABHU, 2001), enquanto que o método gráfico leva a vantagem de apresentar três principais resultados possíveis: alta, média ou baixa prioridade. Quanto ao nível de detalhamento das priorizações e complexidade, o método tradicional apresenta vantagens, respectivamente pela quantidade de informações reunidas, e pela simplicidade, uma vez que o procedimento para a formação do ranking de priorização resume-se ao produto entre os valores dos três índices considerados. 
Isto salienta a importância do NPR no estabelecimento das prioridades, mas que não deve ser usado com exclusividade. Uma atenção especial deve ser dada às falhas com maior grau de severidade, que se destacam com auxílio do método gráfico. Tal constatação converge com a visão de Helman e Andery (1995), que salientam que as falhas com maior NPR "deverão ser tratadas prioritariamente", no entanto, advertem os autores que uma falha com remota possibilidade de ocorrer, mas que seja extremamente grave (alta severidade), "merecerá uma grande atenção", ou seja, nem sempre a NPR deverá ser utilizada com exclusividade na priorização de falhas.

$\mathrm{Na}$ Tabela 5, são relacionadas as causas associadas aos quatro modos de falha de maior risco e os respectivos efeitos merecedores de maior atenção (localizados na região de alta prioridade de risco).

As causas de falha que afetam os modos potenciais de falha, com maior frequência, são as causas C1, C2 e C16 seguidas de C13 e C24, sendo aquelas que, priori-

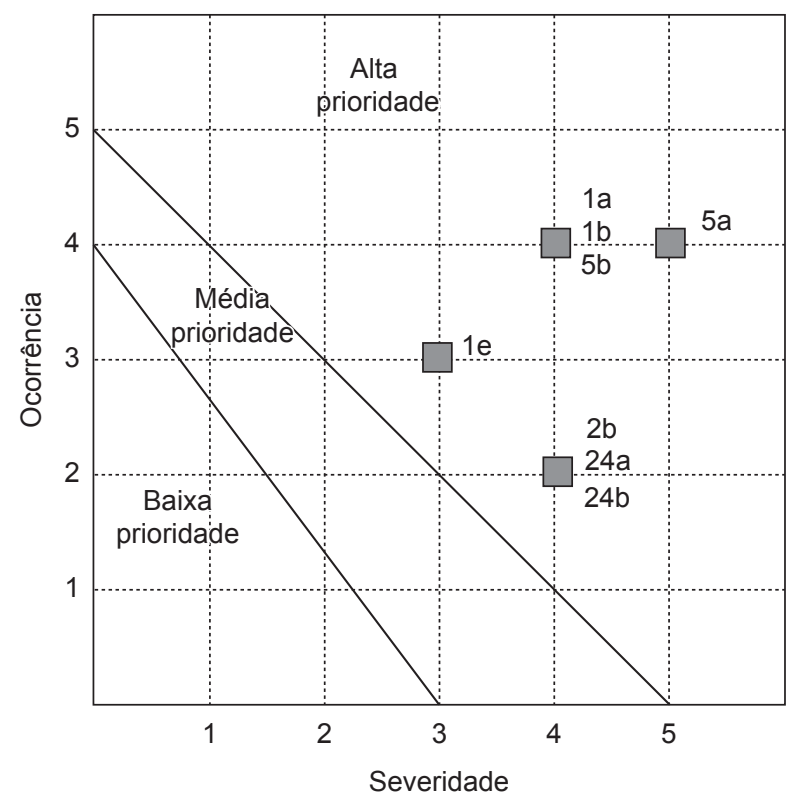

Figura 1. Método gráfico para determinação das prioridades.

Tabela 4. Comparação do método gráfico e NPR para os principais modos de falha.

\begin{tabular}{ccc}
\hline Ordem & Modo de falha/efeito & NPR \\
\hline 1 & $5 \mathrm{a}$ & 60 \\
2 & $5 \mathrm{~b}$ & 48 \\
3 & $1 \mathrm{a} / \mathrm{b}$ & 36 \\
4 & $2 \mathrm{~b} / 24 \mathrm{a} / 24 \mathrm{~b}$ & 16 \\
5 & $1 \mathrm{e}$ & 27 \\
\hline
\end{tabular}

tariamente, devem ser consideradas em planos de ação preventiva.

O modo de falha "impossibilidade de realizar colheita no momento adequado" (5a), que apresentou prioridade máxima no método gráfico e o maior NPR, tem como causa a ocorrência de chuvas e ventos fortes (C12). A debulha, indicada como efeito deste modo de falha, corresponde à abertura natural das síliquas expelindo os grãos, gerando perdas significativas. Não é possível eliminar este modo de falha, mas o acompanhamento, por parte do responsável técnico, das previsões meteorológicas, pode auxiliar na decisão de antecipar o início da colheita. Embora gerando perdas, possibilita que sejam menores que as ocasionadas pelo modo de falha.

\section{Conclusões}

O objetivo deste artigo foi demonstrar a viabilidade do uso da técnica FMEA, na determinação de ações preventivas para a maximização dos fatores de produção num processo de cultivo agrícola.

O setor agrícola possui algumas características próprias, razão pela qual foram feitas algumas adaptações para análise desse tipo de processo. A aplicação foi ilustrada por meio de um estudo de caso em uma lavoura de canola na Escola-Fazenda da Sociedade Educacional Três de Maio (SETREM) na região noroeste do Rio Grande do Sul. A análise teve como foco a produção primária da canola, cujo processo foi dividido nos subprocessos: escolha da área e insumos, sistematização da área de cultivo, semeadura, tratos culturais e colheita. Este artigo apresentou uma metodologia para priorizar modos de falha e seus efeitos associados, para a determinação de ações preventivas, visando aperfeiçoar as atividades no cultivo agrícola de canola, usando a técnica FMEA, com foco no subprocesso colheita.

Em termos de contribuições teóricas, tanto o levantamento das aplicações atuais da ferramenta FMEA, quanto a variedade de critérios para a determinação de prioridades, forneceram subsídios importantes para $\mathrm{o}$ desenvolvimento da aplicação realizada, que carrega na sua essência os princípios da FMEA, considerando as peculiaridades do setor agrícola. A determinação de prioridades dos modos de falha foi feita de forma comparativa, por meio do NPR e de um método gráfico, indicando convergências e divergências de resultados, mostrando a importância do método tradicional, porém sugerindo que este não deve ser usado com exclusividade. A realização deste estudo proporcionou uma reflexão acerca dos métodos de determinação de prioridades usados na ferramenta FMEA.

A abordagem usada serviu para demonstrar a viabilidade do uso da técnica FMEA na determinação de ações 
Tabela 5. Causas associadas aos modos de falha/efeitos de maior risco no subprocesso colheita de canola.

\begin{tabular}{|c|c|c|c|c|c|c|c|c|c|}
\hline \multicolumn{2}{|r|}{ Causa e descrição } & \multicolumn{8}{|c|}{ Modo de falha/efeitos } \\
\hline & & $5 \mathbf{a}$ & $1 \mathbf{a}$ & 1b & $5 \mathbf{b}$ & $2 \mathbf{b}$ & $24 \mathbf{a}$ & $24 b$ & 1e \\
\hline $\mathrm{C} 1$ & Erro/negligência do responsável técnico & & $\mathrm{X}$ & $\mathrm{X}$ & & $\mathrm{X}$ & $\mathrm{X}$ & $\mathrm{X}$ & $\mathrm{X}$ \\
\hline $\mathrm{C} 2$ & Erro do operador & & $\mathrm{X}$ & $\mathrm{X}$ & & $\mathrm{X}$ & $\mathrm{X}$ & $\mathrm{X}$ & $\mathrm{X}$ \\
\hline $\mathrm{C} 12$ & Ocorrência de ventos fortes/chuva & $\mathrm{X}$ & & & $\mathrm{X}$ & & & & \\
\hline $\mathrm{C} 13$ & $\begin{array}{l}\text { Erro de amostragem de colheita para } \\
\text { verificação da amostragem dos grãos }\end{array}$ & & $\mathrm{X}$ & $\mathrm{X}$ & & $\mathrm{X}$ & & & $\mathrm{X}$ \\
\hline $\mathrm{C} 16$ & Inadequado treinamento do operador & & $\mathrm{X}$ & $\mathrm{X}$ & & $\mathrm{X}$ & $\mathrm{X}$ & $\mathrm{X}$ & $\mathrm{X}$ \\
\hline $\mathrm{C} 24$ & Erro na leitura da umidade da amostra & & $\mathrm{X}$ & $\mathrm{X}$ & & $\mathrm{X}$ & & & X \\
\hline
\end{tabular}

preventivas para aperfeiçoar processos de cultivo agrícola. Sobre o sistema produtivo analisado, cujo cultivo e pesquisas são recentes no Brasil, embora já tenham sido desenvolvidos vários trabalhos relacionados ao seu manejo, nenhum deles apoia-se no referencial teórico proposto e usado nesta pesquisa. A técnica não apenas serviu para priorizar modos de falha e seus efeitos associados, mas também documentou o subpro- cesso colheita da canola, listando as causas atuantes no processo produtivo e detectando as prioritárias de atenção.

Ao longo do desenvolvimento dos trabalhos, abriram-se alternativas para a continuidade da pesquisa. Uma alternativa já colocada em prática foi prolongar a aplicação para os demais subprocessos que compõem a produção primária da canola.

\title{
Failure mode and effect analysis in the optimization of production factors in the agro cultivation: subprocess harvest of canola
}

\begin{abstract}
The agricultural sector has been facing an intense process of transformation and modernization. Nevertheless, it can still be considered underdeveloped if compared to other economic segments, regarding the utilization of new technologies and administrative techniques, resulting problems that deserve consideration. This Article presents a methodology to prioritize problems and their related effects to determine preventive measures, aiming at improving processes of canola cultivation, using the FMEA technique focusing on harvest. The agricultural sector has some particular techniques, which is the reason for some adjustments in order to analyze this type of process. The application was illustrated through an experiment in a plantation of canola at the farm-school of sociedade educacional três de maio (SETREM). The determination of priorities of potential problems was done comparatively through RPN (risk priority number) and a graphic method.
\end{abstract}

Keywords: FMEA. Canola plantation. Harvest of canola. Failures prioritization.

\section{Referências bibliográficas}

BEN-DAYA, M.; RAOUF, A. A revised failure mode and effect analysis model. International Journal of Quality \& Reliability Management, v. 13, n. 1, p. 43-47, 1996.

BERTOLINI, M.; BEVILACQUA, M.; MASSINI, R. FMECA approach to product traceability in the food industry. Food Control, v. 17, n. 2, p. 137-145, 2006.

BRADY, N. C. Natureza e propriedade dos solos. Rio de Janeiro: Freitas Bastos, 1979.
CHANG, C.; LIU, P.; WEI, C. Failure mode and effects analysis using grey theory. Integrated Manufacturing Systems, v. 12, n. 3, p. 211-216, 2001

COTNAREANU, T. Old tools - new uses: equipment FMEA. Quality Progress, v. 32, n. 12, p. 48-52, 1999.

ANÁLISE de modo e efeitos de falha potencial (FMEA): manual de referência. São Paulo: ANFAVEA, 2001. 72 p. 
FERNANDES, J. M. R. Proposição de abordagem integrada de métodos da qualidade baseada no FMEA. Curitiba, 2005. 105 p. Dissertação (Mestrado em Engenharia de Produção e Sistemas) - Pontifícia Universidade Católica do Paraná.

GARRAFA, M. Aplicação de FMEA na otimização dos fatores de produção da canola. Santa Maria, 2005. 166 p. Dissertação (Mestrado em Engenharia de Produção) - Universidade Federal de Santa Maria.

GARRAFA, M.; ROSA, L. C. Priorização de ações em cultivo de canola (Brassica napus L. var.oleifera) na Escola-Fazenda da SETREM - subprocesso semeadura. In: ENCONTRO NACIONAL DE ENGENHARIA DE PRODUÇÃO, 24., 2004, Florianópolis. Anais... Rio de Janeiro: ABEPRO, 2004. CD-ROM.

GILCHRIST, W. Modelling failure modes and effect analysis. International Journal of Quality \& Reliability Management, v. 10, n. 5, p. 16-23, 1993.

GUIMARÃES, A. C. F.; LAPA, C. M. F. Fuzzy FMEA applied to PWR chemical and volume control systems. Progress in Nuclear Energy, v. 44, n. 3, p. 191-213, 2004.

HELMAN, H.; ANDERY, P. R. P. Análise de falhas (aplicação dos métodos de FMEA - FTA). Belo Horizonte: Fundação Christiano Ottoni, 1995.

HSIAO, S. W. Concurrent design method for developing a new product. International Journal of Industrial Ergonomics, v. 29, n. 1, p. 41-55, 2002.

LEAL, F.; PINHO, A. F.; ALMEIDA, D. A. Análise de falhas através da aplicação do FMEA e da teoria Grey. In: ENEGEP, 25., 2005, Porto Alegre. Anais... Porto Alegre: UFRGS, 2005. CD-Rom.

LEE, W. K. Risk assessment modeling in aviation safety management. Journal of Air Transport Management, v. 12, n. 5 , p. 267-273, 2006.

McCAIN, C. Using an FMEA in a service setting. Quality Progress, v. 39, n. 9, p. 24-29, 2006.

PALADY, P.FMEA: análise dos modos de falha e efeitos: prevendo e prevenindo problemas antes que ocorram. São Paulo: IMAM, 1997.

PAPARELLA, S. Failure mode and effects analysis: a useful tool for risk identification and injury prevention. Journal of Emergency Nursing, v. 33, n. 4, p. 367-371, 2007.

PILLAY, A.; WANG, J. Modified failure mode and effects analysis using approximate reasoning. Reliability Engineering and System Safety, v. 79, n. 1, p. 69-85, 2003.

PRICE, C. J.; TAYLOR, N. S. Automated multiple failure FMEA. Reliability Engineering and System Safety, v. 76, n. 1, p. 1-10, 2002.
PUENTE, J.; PINO, R.; PRIORE, P.; FUENTE, D. A decision support system for applying failure mode and effects analysis. International Journal of Quality \& Reliability Management, v. 19, n. 2, p. 137-150, 2002.

REID, R. D. FMEA: something old, something new. Quality Progress, v. 38, n. 5, p. 90-93, 2005.

REILING, J. G.; KNUTZEN, B. L.; STOECKLEIN, M. FMEA: the cure for medical errors. Quality Progress, v. 36, n. 8, p. 67-71, 2003.

SANKAR, N. R.; PRABHU, B. S. Modified approach for priorization of failures in a system failure mode and effects analysis. International Journal of Quality \& Reliability Management, v. 18, n. 3, p. 324-335, 2001.

SEYED-HOSSEINI, S. M.; SAFEI, N.; ASGHARPOUR, M. J. Repriorization of failures in a system failure mode and effect analysis by decision making trial and evaluation laboratory technique. Reliability Engineering and System Safety, v. 91, n. 8 , p. $872-881,2006$.

SPATH, P. L. Using failure mode and effects analysis to improve patient safety. AORN Journal, v. 78, n. 1, p. 15-37, 2003.

TOMM, G. O. Cultivo de Canola. Passo Fundo: Embrapa Trigo, 2007. Embrapa Trigo. Sistemas de produção, 3. Disponível em: $<$ http://sistemasdeproducao.cnptia.embrapa.br/FontesHTML/ Canola/CultivodeCanola/index.htm $>$. Acesso em: 20 de Dezembro de 2007.

TOMM, G. O. Manual para cultivo da canola. Passo Fundo: Camera Indústria e Comércio, 2003.

TOMM, G. O. Situação atual e perspectivas da canola no Brasil. Passo Fundo: Embrapa Trigo, 2000. Embrapa Trigo. Comunicado técnico online, 58. Disponível em: <http:// www.cnpt.embrapa.br/biblio/index.htm>. Acesso em: $11 \mathrm{de}$ Novembro de 2007.

TRUCCO, P.; CAVALLIN, M. A quantitative approach to clinical risk assessment: the CREA method. Safety Science, v. 44, n. 6 , p. 491-513, 2006.

VANDENBRANDE, W. W. How to use FMEA to reduce the size of your quality toolbox. Quality Progress, v. 31, n. 11, p. 97-100, 1998.

WELBORN, C. Using FMEA to assess outsourcing risk. Quality Progress, v. 40, n. 8, p. 17-21, 2007.

YADAV, O. P.; SINGH, N.; GOEL, P. S. Reliability demonstration test planning: a three dimensional consideration. Reliability Engineering and System Safety, v. 91, n. 8, p. 882-893, 2006.

YIN, R. Estudo de caso: planejamento e métodos. Porto alegre: Bookman, 2005. 


\section{Apêndice}

Apêndice 1. A estruturação da FMEA para o subprocesso colheita da canola.

\begin{tabular}{|c|c|c|c|c|c|c|c|c|}
\hline Requisitos & $\begin{array}{l}\text { Modo de falha } \\
\text { potencial }\end{array}$ & Efeito da falha & $\mathbf{S}$ & $\begin{array}{l}\text { Causas da } \\
\text { falha }\end{array}$ & $\mathbf{O}$ & $\begin{array}{c}\text { Controles atuais do } \\
\text { processo }\end{array}$ & D & NPR \\
\hline \multirow[t]{5}{*}{$\begin{array}{l}\text { Fazer colheita } \\
\text { em momento } \\
\text { adequado }\end{array}$} & $\begin{array}{l}\text { Colheita com teor de } \\
\text { umidade dos grãos } \\
\text { maior que } 18 \% \text { (1) }\end{array}$ & $\begin{array}{l}\text { Grãos muito úmidos (a) } \\
\text { Excessivos descontos por } \\
\text { umidade (b) } \\
\text { Presença de grãos verdes (c) } \\
\text { Presença de grãos mal } \\
\text { formados (d) } \\
\text { Má debulha (e) } \\
\text { Desconto por impurezas (f) }\end{array}$ & $\begin{array}{l}2 \\
3 \\
2\end{array}$ & $\begin{array}{l}\mathrm{C} 1 \\
\mathrm{C} 13 \\
\mathrm{C} 24 \\
\mathrm{C} 2 \\
\mathrm{C} 16\end{array}$ & 3 & $\begin{array}{l}\text { Detecção: } \\
\text { - monitorar umidade quando } \\
40-60 \% \text { das sementes das } \\
\text { síliquas da parte central do } \\
\text { caule principal mudarem da cor } \\
\text { verde para marrom } \\
\text { - testar amostra em medidor de } \\
\text { umidade }\end{array}$ & 3 & $\begin{array}{l}36 \\
36 \\
18 \\
18 \\
27 \\
18\end{array}$ \\
\hline & $\begin{array}{l}\text { Colheita com teor de } \\
\text { umidade dos grãos } \\
\text { muito baixa (2) }\end{array}$ & $\begin{array}{l}\text { Debulha (a) } \\
\text { Perda de grãos (b) } \\
\text { Quebra de grãos no } \\
\text { processo de trilha (c) } \\
\text { Excessivo desconto por } \\
\text { impurezas (d) }\end{array}$ & $\begin{array}{l}3 \\
4\end{array}$ & $\begin{array}{l}\mathrm{C} 1 \\
\mathrm{C} 13 \\
\mathrm{C} 24 \\
\mathrm{C} 2 \\
\mathrm{C} 16\end{array}$ & 2 & $\begin{array}{l}\text { Detecção: } \\
\text { - monitorar umidade a partir } \\
\text { do momento em que } 40-60 \% \\
\text { das sementes das síliquas da } \\
\text { parte central do caule principal } \\
\text { mudarem da cor verde para } \\
\text { marrom } \\
\text { - testar amostra em medidor de } \\
\text { umidade }\end{array}$ & 2 & $\begin{array}{r}12 \\
16 \\
8 \\
8\end{array}$ \\
\hline & $\begin{array}{l}\text { Realização de colheita } \\
\text { no início da manhã e } \\
\text { final de tarde (3) }\end{array}$ & $\begin{array}{l}\text { Elevado peso de massa } \\
\text { verde que passa pela colhedeira } \\
\text { (a) } \\
\text { Dificuldade de separação dos } \\
\text { grãos da palha (b) }\end{array}$ & 3 & $\begin{array}{l}\mathrm{C} 2 \\
\mathrm{C} 12 \\
\mathrm{C} 10 \\
\mathrm{C} 16\end{array}$ & 2 & $\begin{array}{l}\text { Detecção: } \\
\text { - testar amostra quanto ao } \\
\text { comportamento das síliquas } \\
\text { (toque e a presença de grãos na } \\
\text { palha lançada à lavoura) }\end{array}$ & 1 & $\begin{array}{l}4 \\
6\end{array}$ \\
\hline & $\begin{array}{l}\text { Realização de colheita } \\
\text { nas horas mais quentes e } \\
\text { secas do dia (4) }\end{array}$ & $\begin{array}{l}\text { Síliquas muito secas e sensíveis } \\
\text { ao toque (a) } \\
\text { Excessiva debulha na } \\
\text { plataforma (b) }\end{array}$ & 3 & $\begin{array}{l}\mathrm{C} 2 \\
\mathrm{C} 13 \\
\mathrm{C} 10 \\
\mathrm{C} 16\end{array}$ & 2 & $\begin{array}{l}\text { Detecção: } \\
\text { - testar amostra quanto ao } \\
\text { comportamento das síliquas } \\
\text { (toque e a presença de grãos na } \\
\text { palha lançada à lavoura) }\end{array}$ & 1 & $\begin{array}{l}6 \\
6\end{array}$ \\
\hline & $\begin{array}{l}\text { Impossibilidade de } \\
\text { realizar colheita no } \\
\text { momento adequado (5) }\end{array}$ & $\begin{array}{l}\text { Debulha (a) } \\
\text { Excesso de umidade (b) }\end{array}$ & $\begin{array}{l}5 \\
4\end{array}$ & $\mathrm{C} 12$ & 3 & $\begin{array}{l}\text { Prevenção: } \\
\text { - antecipar a colheita }\end{array}$ & 4 & $\begin{array}{l}60 \\
48\end{array}$ \\
\hline $\begin{array}{l}\text { Iniciar colheita } \\
\text { em áreas sem } \\
\text { plantas daninhas }\end{array}$ & $\begin{array}{l}\text { Iniciar colheita nas áreas } \\
\text { infestadas com plantas } \\
\text { daninhas (6) }\end{array}$ & $\begin{array}{l}\text { Disseminação de espécies } \\
\text { daninhas em áreas livres (a) }\end{array}$ & 2 & $\begin{array}{l}\mathrm{C} 2 \\
\mathrm{C} 16\end{array}$ & 2 & $\begin{array}{l}\text { Prevenção: } \\
\text { - treinar operador } \\
\text { Detecção: } \\
\text { - observar as áreas livres de } \\
\text { plantas daninhas e as infestadas }\end{array}$ & 1 & 4 \\
\hline $\begin{array}{l}\text { Retirar arco } \\
\text { divisor da lateral } \\
\text { da plataforma }\end{array}$ & $\begin{array}{l}\text { Não retirar o arco } \\
\text { divisor da lateral da } \\
\text { plataforma (7) }\end{array}$ & $\begin{array}{l}\text { Debulha pelo toque do arco nas } \\
\text { plantas (a) } \\
\text { Perda de grãos (b) }\end{array}$ & $\begin{array}{l}2 \\
2\end{array}$ & $\begin{array}{l}\mathrm{C} 1 \\
\mathrm{C} 2\end{array}$ & 3 & $\begin{array}{l}\text { Prevenção: } \\
\text { - treinar operador } \\
\text { - retirar arco na preparação da } \\
\text { colhedeira para a operação de } \\
\text { colheita }\end{array}$ & 1 & $\begin{array}{l}6 \\
6\end{array}$ \\
\hline $\begin{array}{l}\text { Fixar mangueira } \\
\text { de } 1 / 2 " \text { ' atrás das } \\
\text { navalhas, em } \\
\text { toda largura da } \\
\text { plataforma }\end{array}$ & $\begin{array}{l}\text { Não colocação de } \\
\text { mangueira atrás das } \\
\text { navalhas em toda } \\
\text { extensão da } \\
\text { plataforma (8) }\end{array}$ & $\begin{array}{l}\text { Queda de grãos ao solo devido } \\
\text { à inclinação das plantas em } \\
\text { direção à barra de corte (a) } \\
\text { Perda de grãos (b) }\end{array}$ & $\begin{array}{l}3 \\
3\end{array}$ & $\mathrm{C} 1$ & 2 & $\begin{array}{l}\text { Prevenção: } \\
\text { - colocar mangueira após as } \\
\text { navalhas na preparação da } \\
\text { colhedeira para a operação de } \\
\text { colheita }\end{array}$ & 1 & $\begin{array}{l}6 \\
6\end{array}$ \\
\hline $\begin{array}{l}\text { Redução do } \\
\text { número de } \\
\text { "aspas" do } \\
\text { molinete }\end{array}$ & $\begin{array}{l}\text { Não redução do } \\
\text { número de "aspas" do } \\
\text { molinete (9) }\end{array}$ & $\begin{array}{l}\text { Debulha das síliquas por } \\
\text { contato com as “aspas” (a) } \\
\text { Perda de grãos (b) }\end{array}$ & $\begin{array}{l}3 \\
3\end{array}$ & $\begin{array}{l}\mathrm{C} 1 \\
\mathrm{C} 2 \\
\mathrm{C} 16\end{array}$ & 2 & $\begin{array}{l}\text { Prevenção: } \\
\text { - treinar operador } \\
\text { - retirar duas "aspas" a cada } \\
\text { três, por ocasião da preparação } \\
\text { da colhedeira }\end{array}$ & 1 & $\begin{array}{l}6 \\
6\end{array}$ \\
\hline $\begin{array}{l}\text { Regulagem do } \\
\text { molinete }\end{array}$ & $\begin{array}{l}\text { Não efetuar recuo do } \\
\text { molinete (10) }\end{array}$ & $\begin{array}{l}\text { Debulha das síliquas por } \\
\text { contato das plantas com as } \\
\text { barras do molinete (a) } \\
\text { Perda de grãos (b) }\end{array}$ & $\begin{array}{l}2 \\
2\end{array}$ & $\begin{array}{l}\mathrm{C} 1 \\
\mathrm{C} 2 \\
\mathrm{C} 16\end{array}$ & 2 & $\begin{array}{l}\text { Prevenção: } \\
\text { - treinar operador } \\
\text { Detecção: } \\
\text { - regulagem do recuo do mo- } \\
\text { linete, permitindo que apenas } \\
\text { as "aspas" se introduzam na } \\
\text { cultura }\end{array}$ & 1 & $\begin{array}{l}4 \\
4\end{array}$ \\
\hline
\end{tabular}


Apêndice 1. Continuação...

\begin{tabular}{|c|c|c|c|c|c|c|c|c|}
\hline \multirow[t]{4}{*}{ Requisitos } & $\begin{array}{l}\text { Modo de falha } \\
\text { potencial }\end{array}$ & Efeito da falha & $\mathbf{S}$ & $\begin{array}{l}\text { Causas da } \\
\text { falha }\end{array}$ & $\mathbf{O}$ & $\begin{array}{c}\text { Controles atuais do } \\
\text { processo }\end{array}$ & D & NPR \\
\hline & $\begin{array}{l}\text { Não efetuar ajuste da } \\
\text { altura do molinete (11) }\end{array}$ & $\begin{array}{l}\text { Debulha das síliquas por } \\
\text { contato das plantas com as } \\
\text { barras do molinete (a) } \\
\text { Perda de grãos (b) }\end{array}$ & 2 & $\begin{array}{c}\mathrm{C} 1 \\
\mathrm{C} 2 \\
\mathrm{C} 16\end{array}$ & 1 & $\begin{array}{l}\text { Prevenção: } \\
\text { - treinar operador } \\
\text { Detecção: } \\
\text { - regular colhedora, permitindo } \\
\text { que apenas as "aspas" sejam } \\
\text { introduzidas na cultura }\end{array}$ & 1 & $\begin{array}{l}2 \\
2\end{array}$ \\
\hline & $\begin{array}{l}\text { Velocidade muito alta do } \\
\text { molinete (12) }\end{array}$ & $\begin{array}{l}\text { Debulha de síliquas por } \\
\text { impacto muito forte do } \\
\text { molinete com as plantas (a) } \\
\text { Perda de grãos (b) }\end{array}$ & $\begin{array}{l}3 \\
3\end{array}$ & $\begin{array}{c}\mathrm{C} 1 \\
\mathrm{C} 2 \\
\mathrm{C} 16\end{array}$ & 2 & $\begin{array}{l}\text { Prevenção: } \\
\text { - treinar operador } \\
\text { Detecção: } \\
\text { - regular colhedora, mantendo } \\
\text { a velocidade do molinete } \\
\text { pouco superior à velocidade de } \\
\text { deslocamento da máquina }\end{array}$ & 1 & $\begin{array}{l}6 \\
6\end{array}$ \\
\hline & $\begin{array}{l}\text { Velocidade muito baixa } \\
\text { do molinete ( } 13 \text { ) }\end{array}$ & $\begin{array}{l}\text { Debulha das síliquas por } \\
\text { tempo excessivo de contato dos } \\
\text { molinetes com a cultura (a) } \\
\text { Perda de grãos (b) }\end{array}$ & $\begin{array}{l}2 \\
2\end{array}$ & $\begin{array}{c}\mathrm{C} 1 \\
\mathrm{C} 2 \\
\mathrm{C} 16\end{array}$ & 2 & $\begin{array}{l}\text { Prevenção: } \\
\text { - treinar operador } \\
\text { Detecção: } \\
\text { - regular colhedora, mantendo } \\
\text { a velocidade do molinete } \\
\text { pouco superior à velocidade de } \\
\text { deslocamento da máquina }\end{array}$ & 1 & $\begin{array}{l}4 \\
4\end{array}$ \\
\hline \multirow[t]{2}{*}{$\begin{array}{l}\text { Adequar altura } \\
\text { da barra de corte }\end{array}$} & $\begin{array}{l}\text { Corte muito baixo das } \\
\text { plantas (14) }\end{array}$ & $\begin{array}{l}\text { Debulha das síliquas devido o } \\
\text { impacto das navalhas com o } \\
\text { caule (a) } \\
\text { Perda de grãos (b) }\end{array}$ & $\begin{array}{l}2 \\
2\end{array}$ & $\begin{array}{l}\mathrm{C} 1 \\
\mathrm{C} 2\end{array}$ & 2 & $\begin{array}{l}\text { Prevenção: } \\
\text { - treinar operador } \\
\text { Detecção: } \\
\text { - visual e constante, com corte } \\
\text { realizado logo abaixo dos } \\
\text { primeiros ramos produtivos }\end{array}$ & 1 & $\begin{array}{l}4 \\
4\end{array}$ \\
\hline & $\begin{array}{l}\text { Corte muito alto das } \\
\text { plantas }(15)\end{array}$ & $\begin{array}{l}\text { Síliquas aderidas ao caule, sem } \\
\text { serem colhidas (a) } \\
\text { Perda de grãos (b) }\end{array}$ & $\begin{array}{l}2 \\
2\end{array}$ & $\mathrm{C} 2$ & 1 & $\begin{array}{l}\text { Detecção: } \\
\text { - visual e constante, com corte } \\
\text { realizado logo abaixo dos } \\
\text { primeiros ramos produtivos }\end{array}$ & 1 & $\begin{array}{l}2 \\
2\end{array}$ \\
\hline $\begin{array}{l}\text { Ajustar altura } \\
\text { do caracol }\end{array}$ & $\begin{array}{l}\text { Altura muito baixa do } \\
\text { caracol (16) }\end{array}$ & $\begin{array}{l}\text { Debulha excessiva das síliquas } \\
\text { antes de serem conduzidas ao } \\
\text { alimentador (a) } \\
\text { Grãos ficam depositados na } \\
\text { plataforma (b) }\end{array}$ & 2 & $\begin{array}{c}\mathrm{C} 1 \\
\mathrm{C} 2 \\
\mathrm{C} 16\end{array}$ & 2 & $\begin{array}{l}\text { Prevenção: } \\
\text { - treinar operador } \\
\text { Detecção: } \\
\text { - visual, por ocasião da colheita }\end{array}$ & 1 & $\begin{array}{l}4 \\
4\end{array}$ \\
\hline \multirow[t]{2}{*}{$\begin{array}{l}\text { Adequar } \\
\text { velocidade do } \\
\text { ventilador }\end{array}$} & $\begin{array}{l}\text { Velocidade do ventilador } \\
\text { muito alta (17) }\end{array}$ & $\begin{array}{l}\text { Lançamento de grãos junto } \\
\text { com as impurezas, face seu } \\
\text { pequeno tamanho e peso (a) } \\
\text { Perda de grãos (b) }\end{array}$ & $\begin{array}{l}3 \\
3\end{array}$ & $\begin{array}{c}\mathrm{C} 1 \\
\mathrm{C} 2 \\
\mathrm{C} 16\end{array}$ & 1 & $\begin{array}{l}\text { Prevenção: } \\
\text { - treinar operador } \\
\text { Detecção: } \\
\text { - visual, por ocasião da colheita }\end{array}$ & 1 & $\begin{array}{l}3 \\
3\end{array}$ \\
\hline & $\begin{array}{l}\text { Velocidade do ventilador } \\
\text { muito baixa (18) }\end{array}$ & $\begin{array}{l}\text { Má separação das impurezas } \\
\text { dos grãos (a) } \\
\text { Excesso de impurezas (b) }\end{array}$ & $\begin{array}{l}2 \\
2\end{array}$ & $\begin{array}{c}\mathrm{C} 1 \\
\mathrm{C} 2 \\
\mathrm{C} 16\end{array}$ & 2 & $\begin{array}{l}\text { Prevenção: } \\
\text { - treinar operador } \\
\text { Detecção: } \\
\text { - visual, por ocasião da colheita }\end{array}$ & 1 & $\begin{array}{l}4 \\
4\end{array}$ \\
\hline \multirow[t]{2}{*}{$\begin{array}{l}\text { Ajustar } \\
\text { velocidade do } \\
\text { cilindro entre } \\
400-600 \mathrm{rpm}\end{array}$} & $\begin{array}{l}\text { Velocidade do cilindro } \\
\text { maior que } 600 \mathrm{rpm} \text { (19) }\end{array}$ & $\begin{array}{l}\text { Quebra de grãos (a) } \\
\text { Aumento de impurezas (b) }\end{array}$ & $\begin{array}{l}3 \\
2\end{array}$ & $\begin{array}{c}\mathrm{C} 1 \\
\mathrm{C} 2 \\
\mathrm{C} 16\end{array}$ & 1 & $\begin{array}{l}\text { Detecção: } \\
\text { - visual por amostragem, } \\
\text { verificando a qualidade dos } \\
\text { grãos }\end{array}$ & 1 & $\begin{array}{l}3 \\
2\end{array}$ \\
\hline & $\begin{array}{l}\text { Velocidade do cilindro } \\
\text { menor que } 400 \mathrm{rpm}(20)\end{array}$ & $\begin{array}{l}\text { Má debulha (a) } \\
\text { Perda de grãos (b) }\end{array}$ & $\begin{array}{l}3 \\
2\end{array}$ & $\begin{array}{c}\mathrm{C} 1 \\
\mathrm{C} 2 \\
\mathrm{C} 16\end{array}$ & 1 & $\begin{array}{l}\text { Detecção: } \\
\text { - visual por amostragem, } \\
\text { verificando a presença de grãos } \\
\text { na palha lançada à lavoura }\end{array}$ & 1 & $\begin{array}{l}3 \\
2\end{array}$ \\
\hline $\begin{array}{l}\text { Abertura do } \\
\text { côncavo entre } \\
10-12 \mathrm{~mm}\end{array}$ & $\begin{array}{l}\text { Abertura do côncavo } \\
\text { menor que } 10 \mathrm{~mm}(21)\end{array}$ & $\begin{array}{l}\text { Quebra de grãos (a) } \\
\text { Aumento de impurezas (b) }\end{array}$ & $\begin{array}{l}3 \\
2\end{array}$ & $\begin{array}{c}\mathrm{C} 1 \\
\mathrm{C} 2 \\
\mathrm{C} 16\end{array}$ & 2 & $\begin{array}{l}\text { Prevenção: } \\
\text { - treinar operador } \\
\text { Detecção: } \\
\text { - visual por amostragem, } \\
\text { verificando a qualidade dos } \\
\text { grãos }\end{array}$ & 1 & $\begin{array}{l}6 \\
2\end{array}$ \\
\hline
\end{tabular}


Apêndice 1. Continuação...

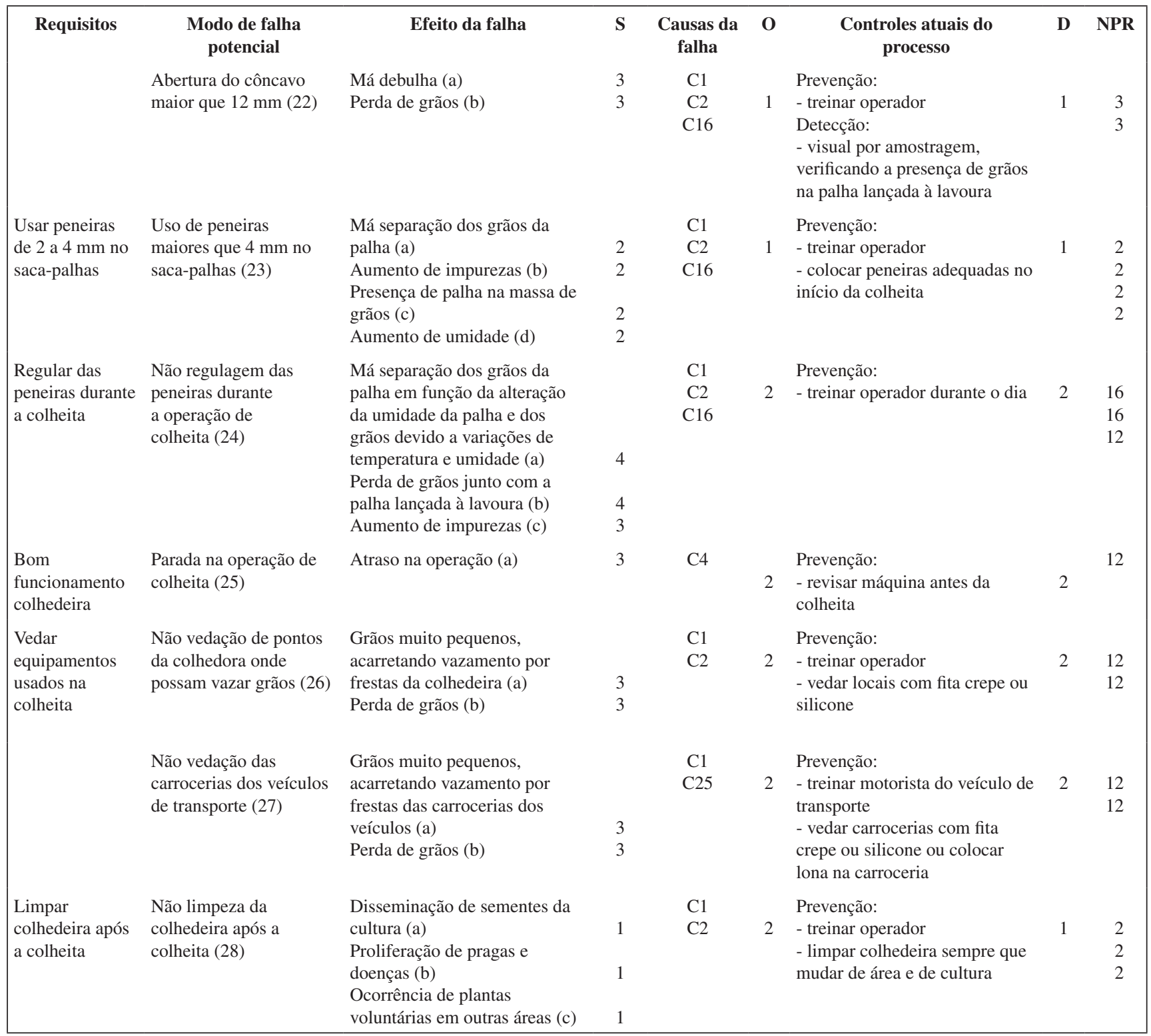


Apêndice 2. Causas de falhas no subprocesso colheita de canola.

\begin{tabular}{|c|c|}
\hline & Causa e descrição \\
\hline $\mathrm{C} 1$ & Erro/negligência do responsável técnico \\
\hline $\mathrm{C} 2$ & Erro do operador \\
\hline $\mathrm{C} 3$ & Colheita com inadequada umidade dos grãos \\
\hline $\mathrm{C} 4$ & Mau funcionamento da colheitadeira \\
\hline $\mathrm{C} 5$ & Não adaptação da colheitadeira \\
\hline C6 & Peneiras inadequadas \\
\hline $\mathrm{C} 7$ & Não regulagem das peneiras durante a operação de colheita \\
\hline $\mathrm{C} 8$ & Não vedação dos elevadores e locais de vazamento de grãos \\
\hline C9 & Não vedação das carrocerias dos veículos de transporte de grãos \\
\hline $\mathrm{C} 10$ & Antecipação da colheita por previsão de chuvas \\
\hline $\mathrm{C} 11$ & Impossibilidade de colheita em momento adequado por ocorrência de chuvas \\
\hline $\mathrm{C} 12$ & Ocorrência de ventos fortes/chuva \\
\hline $\mathrm{C} 13$ & Erro de amostragem de colheita para verificação da amostragem dos grãos \\
\hline $\mathrm{C} 14$ & Início da colheita por áreas infestadas por plantas invasoras \\
\hline $\mathrm{C} 15$ & Colheita em hora inadequada do dia \\
\hline $\mathrm{C} 16$ & Inadequado treinamento do operador \\
\hline $\mathrm{C} 17$ & Não limpeza da colheitadeira após operação \\
\hline $\mathrm{C} 18$ & Má regulagem do molinete \\
\hline $\mathrm{C} 19$ & Altura inadequada da barra de corte \\
\hline $\mathrm{C} 20$ & Altura muito baixa do caracol \\
\hline $\mathrm{C} 21$ & Inadequada velocidade do ventilador \\
\hline $\mathrm{C} 22$ & Incorreta abertura do côncavo \\
\hline $\mathrm{C} 23$ & Velocidade inadequada do cilindro \\
\hline $\mathrm{C} 24$ & Erro na leitura da umidade da amostra \\
\hline $\mathrm{C} 25$ & Erro do motorista do veículo de transporte \\
\hline
\end{tabular}

\section{Sobre os autores}

\section{Leandro Cantorski da Rosa}

Doutor em Engenharia de Produção,

Programa de Pós-Graduação em Engenharia de Produção - PPGEP,

Departamento de Engenharia de Produção e Sistemas, Centro de Tecnologia, Universidade Federal de Santa Maria - UFSM,

Campus Camobi, CEP 97105-900, Santa Maria, RS, Brasil,

e-mail: leski78@ hotmail.com

\section{Marcos Garrafa}

Mestre em Engenharia de Produção,

Faculdade de Administração, Sociedade Educacional Três de Maio - SETREM,

Av. Santa Rosa, 2405, CEP 98910-000, Três de Maio, RS, Brasil,

e-mail: garrafa@setrem.com.br 